\title{
In Vivo Bile Acid Uptake from Terminal Ileum in Cystic Fibrosis
}

\author{
GEOFFREY N. THOMPSON AND GEOFFREY P. DAVIDSON \\ Departments of Chemical Pathology and Gastroenterology, Adelaide Children's Hospital, North Adelaide, \\ South Australia, Australia
}

\begin{abstract}
The cause(s) of excessive fecal bile acid loss in cystic fibrosis (CF) has not yet been fully determined, but in vitro studies have suggested that a primary mucosal defect in ileal bile acid uptake may be of importance. To examine this mechanism in vivo, the terminal ileal uptakes of taurocholate and glycocholate were determined using a marker-perfusion technique in three $\mathrm{CF}$ infants and four controls. Normal and $C F$ ileal conditions were simulated by varying the taurocholate:glycocholate concentration ratio (normal 1:1, CF 1:4) and pH (normal 7.8, CF 6.0) of the perfusate. The mean bile acid uptake under normal perfusate conditions was not significantly different in CF subjects (taurocholate $0.124 \mu \mathrm{mol} / \mathrm{min} / \mathrm{cm}$ ileum $\pm \mathrm{SD}$ 0.127 , glycocholate $0.117 \mu \mathrm{mol} / \mathrm{min} / \mathrm{cm}$ ileum \pm 0.114 ), and controls $(0.142 \pm 0.164$ and $0.115 \pm 0.120$ respectively). Similarly, under CF conditions, bile acid uptake values in CF subjects and controls were similar. The results are not consistent with deranged ileal bile acid reabsorption being a major cause of fecal bile acid loss in CF. (Pediatr Res 23: 323-328, 1988)
\end{abstract}

Abbreviations

CF, cystic fibrosis

G/T ratio, glycine/taurine conjugation ratio

BSP, bromosulfophthalein

HPTLC, high performance thin layer chromatography

Excessive fecal bile acid loss has been well documented in patients with CF (1-3). The loss may predispose to depletion of total bile acid pools (3) and possibly to impaired nutrient absorption. In addition, because of man's limited ability to biosynthesize taurine (4), excessive bile acid loss may deplete taurineconjugated bile acid pools and result in elevation of the $\mathrm{G} / \mathrm{T}$ ratio of bile acids. Elevated $\mathrm{G} / \mathrm{T}$ ratio has been noted frequently in CF (5-7), and may contribute to fat malabsorption (8).

The cause(s) of excessive fecal bile acid loss in CF have not yet been clearly identified. Proposed mechanisms (2) include excessive intraluminal binding of bile acids to food residues, precipitation of bile acids in the acidic duodenal contents of most CF subjects, interference with bile acid absorption by unhydrolyzed triglycerides and/or phospholipids, and defective bile acid uptake in the terminal ileum. Fondacaro et al. (9) have recently proposed on the basis of in vitro measurements of taurocholate uptake that bile acid malabsorption in CF results from a primary mucosal defect in active ileal bile acid transport mechanisms. The finding has not yet been confirmed in vivo,

Received April 28, 1987; accepted November 16, 1987

Correspondence and reprints Dr. G. N. Thompson, Nutrition Research Group, Clinical Research Centre, Watford Road, Harrow, Middlesex HA1 3UJ, England. nor has the ileal transport of other bile acids been examined in $\mathrm{CF}$

Our study was designed to examine the uptake of taurocholate and glycocholate in vivo in the ileum of CF infants with ileostomies after meconium ileus.

\section{METHODS}

Subjects. CF Subjects. Three CF infants (mean age 1.5 months, range $1-2$ ) who had developed the neonatal complication of meconium ileus and required a temporary ileostomy of either the Bishop-Koop (two infants) or double-barrel (one infant) type (Fig. 1) were studied. Ileostomies in these children all gave access to a 10 - to $20-\mathrm{cm}$ segment of intact terminal ileum that had been sited within $25 \mathrm{~cm}$ of the ileocecal valve before surgery. The diagnosis of $\mathrm{CF}$ was based on elevated chloride concentrations (>60 mmol/liter) in at least $100 \mathrm{mg}$ of sweat collected after pilocarpine iontophoresis (10). All CF subjects had pancreatic insufficiency and were taking Pancrease R (Johnson \& Johnson, Skillman, NJ: 1 capsule $/ 90 \mathrm{ml}$ of feed). All were feeding normally on a medium chain triglyceride-based formula.

Controls. Four non-CF infants (mean age 3.2 months, range $2.5-4$ ) were studied as controls. Each infant had a temporary or permanent Bishop-Koop (one infant), double-barrel (one infant), or terminal (two infants) ileostomy (Fig. 1) that gave access to a terminal ileal segment $10-20 \mathrm{~cm}$ in length as described above. All controls were feeding normally on standard infant formulae at the time of study.

Control subject 1 was a prematurely born infant who developed necrotizing enterocolitis requiring total colectomy and terminal ileostomy in the neonatal period. The infant, aged 3 months postterm, had bronchopulmonary dysplasia and required additional oxygen at the time of study but was otherwise healthy. Subject 2, a full-term infant, required a double-barrel ileostomy because of necrotizing enterocolitis that developed after exchange transfusion in the 1st wk of life. No ileum was resected and the distal ileal stump was $2 \mathrm{~cm}$ in length. Subject 3 had Down's syndrome and a cyanotic congenital heart lesion requiring oxygen supplements. He developed necrotizing enterocolitis requiring a terminal ileostomy in the neonatal period but was active and feeding normally at the time of study. Subject 4 had longsegment Hirschspring's disease requiring an ileostomy. The distal ileal loop measured $1 \mathrm{~cm}$ in length. The ileum had been biopsied and was not involved in the disease process.

The two subjects who required oxygen supplements were normoxemic at the time of study. The remaining terminal ileum was macroscopically and microscopically normal in all controls. Studies were performed in all children only when they were fully recovered from the effects of surgery (at least $3 \mathrm{wk}$ postsurgery). All were gaining weight normally and none had excessive fluid loss through the ileostomy.

Marker-perfusion technique. The marker-perfusion technique 


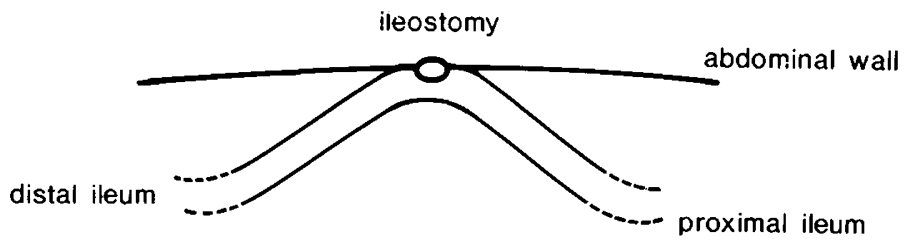

a) BISHOP-KOOP ILEOSTOMY a)

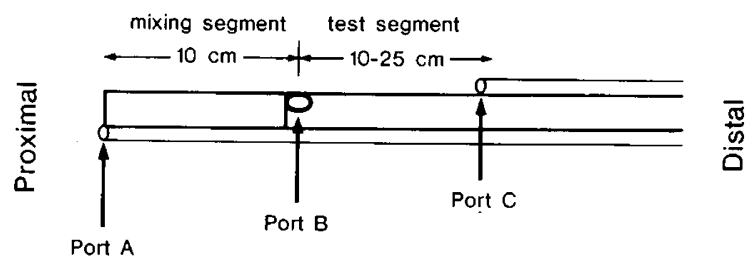

b)

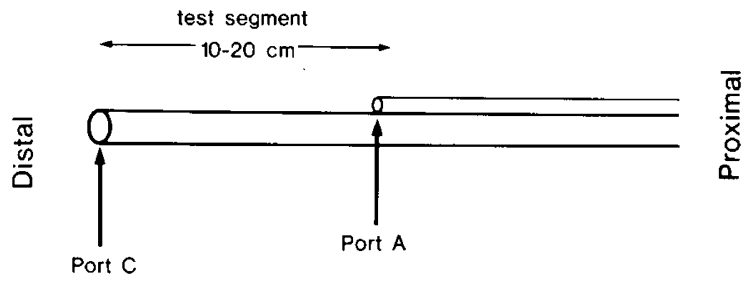

Fig. 2. Tube systems used in marker-perfusion techniques. Infusions were administered through port $\mathrm{A}$ and samples collected through ports $\mathrm{B}$ and C. $a$, triple-lumen tube used with Bishop-Koop and terminal ileostomies. $b$, double-lumen tube used with double-barrel ileostomy.

sedation, and were fed and cared for normally throughout each study.

Perfusate Composition. Glycocholate, taurocholate (sodium salts; Sigma Chemical Co., St. Louis, MO) and electrolytes were added to create solutions of differing $\mathrm{G} / \mathrm{T}$ ratio and $\mathrm{pH}$ and electrolyte composition (Table 1). Two solutions were made up to approximate the conditions found in the ileum of CF subjects (CF pH, CF G/T ratio: $\mathrm{pH}$ of approximately $6, \mathrm{G} / \mathrm{T}$ ratio of $4: 1$ ) and in the ileum of normal subjects (normal $\mathrm{pH}$, normal $\mathrm{G} / \mathrm{T}$ ratio: $\mathrm{pH} 7.8, \mathrm{G} / \mathrm{T}$ ratio $1: 1$ ). A further two solutions were composed of low $\mathrm{pH}$ with normal $\mathrm{G} / \mathrm{T}$ ratio ( $\mathrm{CF} \mathrm{pH}$, normal G/ $\mathrm{T}$ ratio) and normal $\mathrm{pH}$ with elevated $\mathrm{G} / \mathrm{T}$ ratio (normal $\mathrm{pH}$, $\mathrm{CF}$ G/T ratio). BSP $0.01 \% \mathrm{w} / \mathrm{v}$ was added to each solution as a marker. A potential disadvantage of BSP as a marker is that it may bind to proteins, causing an uneven distribution of the marker within intestinal contents (13). The protein content of 15 intestinal fluid samples collected from port B in CF subjects was minimal (mean $2 \mathrm{~g} /$ liter, range 0-4).

Perfusion Method and Sample Collection. Each perfusate was infused via port $\mathrm{A}$ at $1.5 \mathrm{ml} / \mathrm{min}$ for $2 \mathrm{~h}$ using a constant rate infusion pump (IVAC model 700). Solutions were infused in random order over $2 \times 2 \mathrm{~h}$ periods on 2 successive days, or over $4 \times 2 \mathrm{~h}$ periods on a single day. For each solution an equilibration period of $20 \mathrm{~min}$ was allowed. Samples were then collected from port $\mathrm{C}$ by continuous siphonage over five or six 20 -min periods. The expected transit time of ileal contents over the perfused segment is about $5 \mathrm{~min}(15)$. Staggering the sampling so that the proximal sample corresponds to the midpoint of each distal intestinal fluid collection period considerably increases the reproducibility of results of perfusion studies (15). A spot sample was therefore collected from port $\mathrm{B}$ by suction $5 \mathrm{~min}$ after the commencement of each port $C$ collection period. The initial 2$3 \mathrm{ml}$ of aspirate (corresponding to the dead space of the tube in use) was discarded before each sample of approximately $2 \mathrm{ml}$ was collected from port B.

Sample analysis. Intestinal fluid samples were frozen immediately after collection and, together with an aliquot of perfusate, 
Table 1. Composition of perfusates used in marker-perfusion studies

\begin{tabular}{lcccc}
\hline & \multicolumn{4}{c}{ G/T ratio* } \\
\cline { 2 - 5 } & Normal & CF & Normal & CF \\
\cline { 2 - 5 } & \multicolumn{4}{c}{$\mathrm{pH}$ and electrolyte composition $\dagger$} \\
\cline { 2 - 5 } & $\mathrm{CF}$ & $\mathrm{CF}$ & Normal & Normal \\
\hline Bile acids (mmol/liter) & 5 & 2 & 5 & 2 \\
$\quad$ Taurocholate & 5 & 8 & 5 & 8 \\
Glycocholate & 6 & 6 & 7.8 & 7.8 \\
pH & & & & \\
Electrolytes (mmol/liter) & 130 & 130 & 125 & 125 \\
$\quad$ Sodium & 6 & 6 & 8 & 8 \\
Potassium & 86 & 86 & 120 & 120 \\
Chloride & 1.75 & 1.75 & 1.75 & 1.75 \\
Magnesium & 1.0 & 1.0 & 1.1 & 1.1 \\
Calcium & 0.5 & 0.5 & 13 & 13 \\
Bicarbonate & 4.0 & 4.0 & 4.0 & 4.0 \\
Glucose (mmol/liter) & 255 & 255 & 275 & 275 \\
Osmolarity (mosm/kg) & & & \\
\hline
\end{tabular}

* The ratio of glycine:taurine conjugation of bile acids.

+ Composition of 'CF' perfusate was based on analysis of ileal fluid contents from the first $\mathrm{CF}$ subject studied, while composition of normal perfusate was based on normal literature values (14).

were stored at $-20^{\circ} \mathrm{C}$ until assayed. Sample $\mathrm{pH}$ was meaured with a glass $\mathrm{pH}$ meter.

Bile Acids. Bile acids were measured in intestinal fluid samples by HPTLC as previously described (16).

$B S P$. BSP was measured by a method based on that of Oppe and Gibbs (17), except that acidification of the blank solution with $7.5 \mathrm{mmol} /$ liter acetic acid was necessary because many samples of higher $\mathrm{pH}$ exhibited some color change that remained if the usual deionized water was used. Some samples, particularly those from CF subjects, were excessively turbid in neutral or acid solution and became less turbid with alkalinization. The turbidity, which resulted in high absorbance at $580 \mathrm{~nm}$ in blank (acid) solutions and therefore interfered with BSP determination, could be removed by prewashing $1 \mathrm{ml}$ of sample with $5 \mathrm{ml}$ watersaturated spectrophotometric grade ether (Merck, Darmstadt, West Germany). The mean BSP recovered from 11 perfusate solutions assayed by this alternative technique was $98.1 \% \pm \mathrm{SD}$ 6.7 and correlation between BSP values obtained from nonturbid intestinal fluid solutions with and without ether prewashing was good ( $r=0.992, n=8)$. BSP assays of intestinal fluid samples derived from a given perfusate in each individual subject were all performed by the same technique.

Bile acid uptake calculation. Net bile acid uptake was calculated by a method adapted from that described by Fordtran et al. (18):

For subjects with a Bishop-Koop or terminal ileostomy:

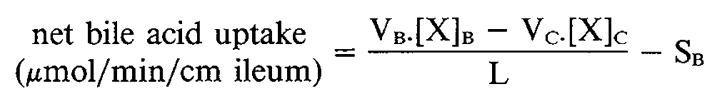

For subjects with a double-barrel ileostomy:

$$
\underset{(\mu \mathrm{mol} / \mathrm{min} / \mathrm{cm} \text { ileum })}{\text { net bile acid uptake }}=\frac{\left.\mathrm{V}_{\mathrm{A} \cdot[\mathrm{X}}\right]_{\mathrm{A}}-\mathrm{V}_{\mathrm{C} \cdot[\mathrm{X}]_{\mathrm{C}}}}{\mathrm{L}}
$$

where $[\mathrm{X}]_{\mathrm{A}}=$ bile acid concentration of perfusate (mmol/liter); $[\mathrm{X}]_{\mathrm{B}}=$ bile acid concentration at port $\mathrm{B}(\mathrm{mmol} / \mathrm{liter}) ;[\mathrm{X}]_{\mathrm{C}}=$ bile acid concentration at port $\mathrm{C}(\mathrm{mmol} / \mathrm{liter}) ; \mathrm{S}_{\mathrm{B}}=$ rate of sample collection at port $\mathrm{B}(\mathrm{ml} / \mathrm{min}) ; \mathrm{L}=$ length of test segment $(\mathrm{cm}) ; \mathrm{V}_{\mathrm{A}}=$ infusion rate at port $\mathrm{A}=1.5 \mathrm{ml} / \mathrm{min} ; \mathrm{V}_{\mathrm{B}}=$ flow rate at port $\mathrm{B}(\mathrm{ml} / \mathrm{min})=\mathrm{V}_{\mathrm{A}}[\mathrm{BSP}]_{\mathrm{A}} /[\mathrm{BSP}]_{\mathrm{B}} ;[\mathrm{BSP}]_{\mathrm{A}}=\mathrm{BSP}$ concentration of perfusate $=100 \mathrm{mg} / \mathrm{liter} ;[\mathrm{BSP}]_{\mathrm{B}}=\mathrm{BSP}$ concentration at port $\mathrm{B}(\mathrm{mg} / \mathrm{liter}) ; \mathrm{V}_{\mathrm{C}}=$ flow rate at port $\mathrm{C}(\mathrm{ml} / \mathrm{min})$ : for Bishop-Koop or terminal ileostomy

$$
\mathrm{V}_{\mathrm{C}}=\mathrm{V}_{\mathrm{B}} \frac{[\mathrm{BSP}]_{\mathrm{B}}}{[\mathrm{BSP}]_{\mathrm{C}}}-\mathrm{S}_{\mathrm{B}}
$$

for double-barrel ileostomy

$$
\mathrm{V}_{\mathrm{C}}=\mathrm{V}_{\mathrm{A}} \cdot \frac{[\mathrm{BSP}]_{\mathrm{A}}}{[\mathrm{BSP}]_{\mathrm{C}}}
$$

$[\mathrm{BSP}]_{\mathrm{C}}=\mathrm{BSP}$ concentration of port $\mathrm{C}(\mathrm{mg} / \mathrm{liter})$.

Binding of bile acids to ileal mucosa has not, to our knowledge, been examined in man. In rats and hamsters, bile acid binding is less than $10 \%$ of uptake (19). Passive binding of bile acids was ignored in our study. The calculations assume constancy of the parameters described by Poiseuille's law, i.e. constancy between ports $\mathrm{A}$ and $\mathrm{C}$ of viscosity of intestinal fluid, and of pressure within, and radius and length of, the ileal segment. The net change in the values of these parameters over a number of time periods could be expected to be minimal. The model is only useful, however, when a mean of uptake values from a number of periods is taken.

Statistical analysis. The unpaired Wilcoxon rank sum test (20) was used to compare bile acid uptake volume in CF and control subjects as the uptake values were of non-Gaussian distribution.

All subjects participated in the study with the informed consent of their parents. The study was approved by the Adelaide Children's Hospital Research Ethics Committee.

\section{RESULTS}

The first 20-min sampling period yielded erratic results in subjects with a Bishop-Koop or terminal ileostomy which suggested that equilibration was incomplete. Uptake values for subsequent periods, however, and for all periods in subjects with a double-barrel ileostomy, were more consistent. In subjects with a double-barrel ileostomy, the lack of proximal intestinal secretions entering the test segment probably shortened the equilibration time. Uptake values from the first 20 -min period in subjects with Bishop-Koop or terminal ileostomy were excluded from further analysis, effectively increasing the equilibration time to $40 \mathrm{~min}$.

Bile acid uptake values for each individual were variable between periods but showed no particular trend. Bile acid uptake values from the $C F$ subject with a double-barrel ileostomy were similar to those of CF subjects with a Bishop-Koop ileostomy. Data from all periods were therefore combined and are presented in Figure 3 and Table 2. Under all conditions of $G / T$ ratio and $\mathrm{pH}$ and electrolyte composition, uptake of both taurocholate and glycocholate appeared to be similar in $\mathrm{CF}$ and control subjects.

Perfusion methods similar to those used in the current study $(11,15,21)$ have, when used for the measurement of electrolyte and water uptake, resulted in large SD of uptake values similar to those noted in Table 2 . Wide variations in results, even within an individual between periods, appear inevitable when using a model that assumes the steady state of the conditions described by Poiseuille's law, in the human intestine, where such steady state conditions cannot be consistently obtained. The similarity between the variability obtained in our study and that obtained elsewhere in normal individuals $(11,12,15)$ suggests the variations did not arise from alteration to the ileum by surgery in subjects in our study.

Before the current perfusion studies, taurocholate and glycocholate levels were measured in intestinal fluid discharged from the ileostomies of two $\mathrm{CF}$ and two control subjects. The ileostomy fluid mean taurocholate concentration in the CF subjects was $0.50 \mathrm{mmol} /$ liter whereas that of glycocholate was $3.5 \mathrm{mmol} / \mathrm{liter}$ (mean $\mathrm{G} / \mathrm{T}$ ratio $7 / 1$ ); both bile acids were below lower limits of detection of the HPTLC method (about $0.01 \mathrm{mmol} / \mathrm{liter}$ ) in ileostomy fluid from each control. 


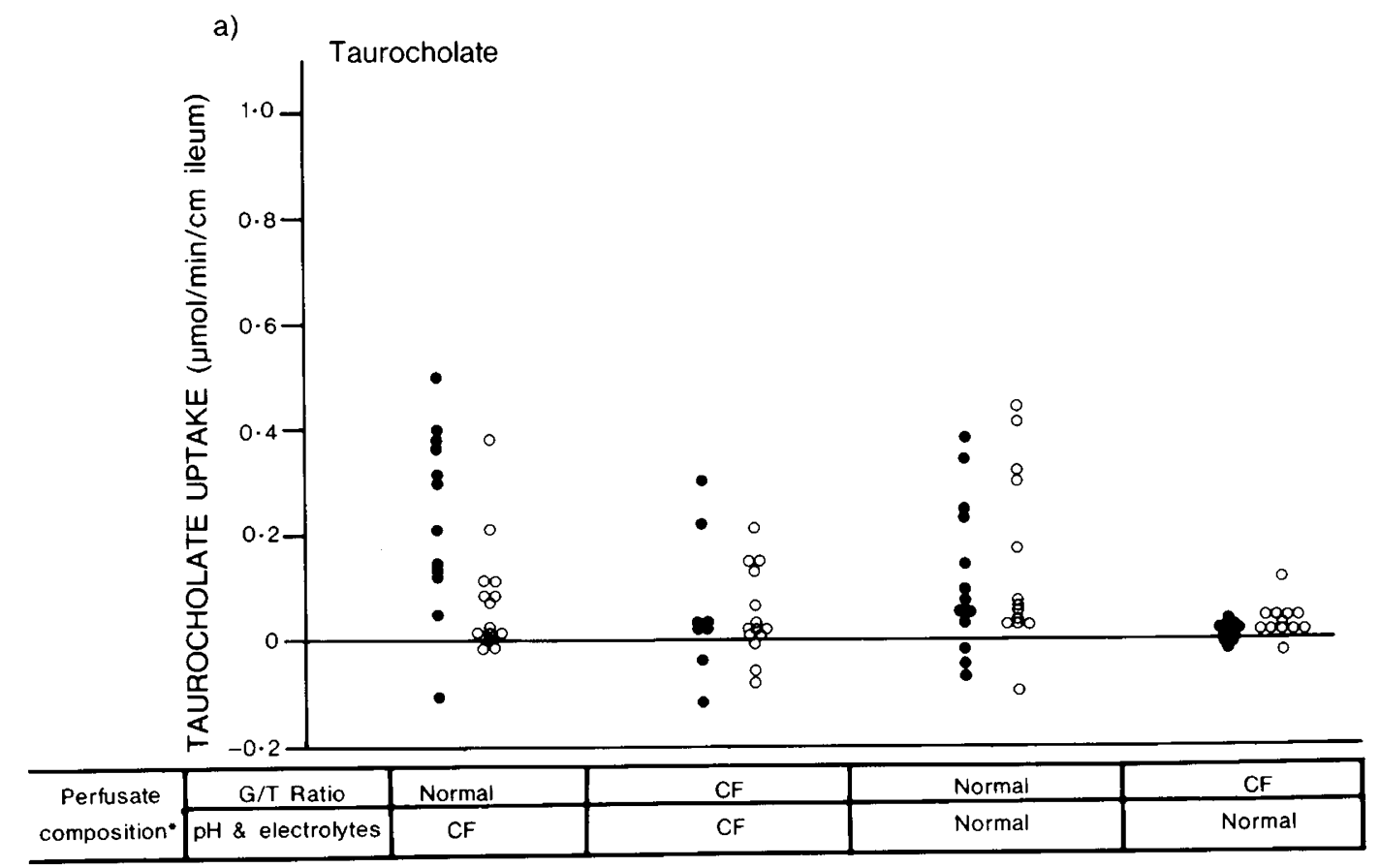

b)

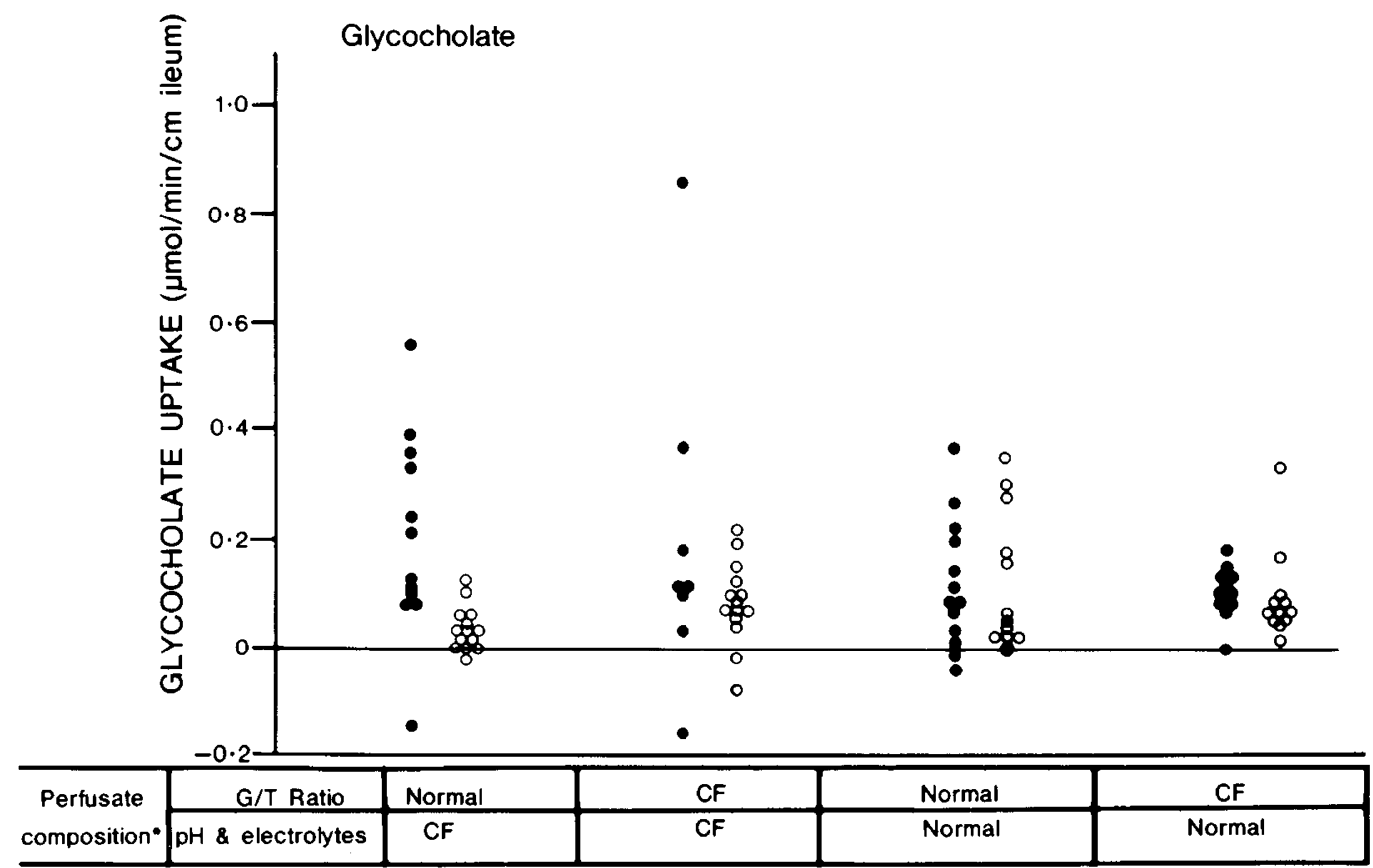

Fig. 3. Bile acid uptake from terminal ileum. Bile acid uptake values from all collection periods at equilibrium are combined for each perfusate. ๑, CF; $\mathrm{O}$, controls. * Perfusates were composed as described in Table 1.

During perfusion of normal perfusate, the $\mathrm{pH}$ values of 10 ileal contents samples collected from each of ports B (mean $\mathrm{pH}$ 8.11) and $\mathrm{C}$ (mean pH 8.38) in one $\mathrm{CF}$ subject was similar to that of the perfusate $(\mathrm{pH} 7.8)$. Similarly, during perfusion of $\mathrm{CF}$ perfusate, the $\mathrm{pH}$ values of four samples collected from each of ports B (mean pH 6.09) and C (mean pH 6.20) in one control subject were similar to that of the perfusate $(\mathrm{pH} 6.0)$. The concentration of bile acids at port $\mathrm{B}$ was similar to that of the perfusate for each perfusate in both CF and control subjects.

\section{DISCUSSION}

Herein we demonstrate no obvious decrease in ileal bile acid uptake rates in CF subjects compared with controls. The controls were slightly older than the $\mathrm{CF}$ subjects, a factor that may be relevant considering the rapid development of intestinal function in infancy. Whereas the exact ontogeny of bile acid uptake is not known in man, the uptake increases with age in the rat (19) and $\operatorname{dog}(22)$, suggesting that age-corrected values in $\mathrm{CF}$ subjects 
Table 2. Bile acid uptake from terminal ileum in CF and control subjects

\begin{tabular}{|c|c|c|c|c|c|}
\hline \multicolumn{2}{|c|}{ Perfusate composition $\dagger$} & \multicolumn{4}{|c|}{$\begin{array}{l}\text { Bile acid uptake }(\mu \mathrm{mol} / \mathrm{min} / \mathrm{cm} \text { ileum, } \\
\text { mean } \pm \mathrm{SD})\end{array}$} \\
\hline $\begin{array}{c}\mathrm{G} / \mathrm{T} \\
\text { ratio }\end{array}$ & $\begin{array}{l}\mathrm{pH} \text { and } \\
\text { electro- } \\
\text { lytes }\end{array}$ & $n \ddagger$ & CF subjects & $n^{*}$ & Controls \\
\hline \multicolumn{6}{|c|}{ Taurocholate } \\
\hline Normal & $\mathrm{CF}$ & 12 & $0.231 \pm 0.166$ & 14 & $0.054 \pm 0.058$ \\
\hline $\mathrm{CF}$ & $\mathrm{CF}$ & 8 & $0.058 \pm 0.127$ & 14 & $0.049 \pm 0.080$ \\
\hline Normal & Normal & 13 & $0.124 \pm 0.127$ & 13 & $0.142 \pm 0.164$ \\
\hline $\mathrm{CF}$ & Normal & 11 & $0.010 \pm 0.017$ & 12 & $0.016 \pm 0.062$ \\
\hline \multicolumn{6}{|c|}{ Glycocholate } \\
\hline Normal & $\mathrm{CF}$ & 12 & $0.200 \pm 0.174$ & 14 & $0.034 \pm 0.038$ \\
\hline $\mathrm{CF}$ & $\mathrm{CF}$ & 8 & $0.194 \pm 0.303$ & 14 & $0.081 \pm 0.075$ \\
\hline Normal & Normal & 13 & $0.117 \pm 0.114$ & 13 & $0.115 \pm 0.120$ \\
\hline CF & Normal & 11 & $0.103 \pm 0.045$ & 12 & $0.089 \pm 0.081$ \\
\hline
\end{tabular}

* The ratio of glycine:taurine conjugation of bile acids.

$\dagger$ As described in Table 1.

$\ddagger$ Number of 20 min-perfusion periods. None of the differences were statistically significant.

would not be lower, although they could be higher, than those in controls. While intensive mucosal function tests could not be undertaken in controls, the normal macroscopic and microscopic mucosal appearance, normal growth, and normal intestinal fluid output suggest that mucosal function was normal. Our results therefore indicate that ileal bile acid uptake is not impaired in CF.

The finding contrasts sharply with that of Fondacaro et al. (9) who demonstrated that taurocholate uptake in ileum from CF subjects in an in vitro model was about $30 \%$ that in control ileum. They proposed that the decreased uptake may be a manifestation of a primary defect in CF. The mean age of their subjects was, however, $16.7 \mathrm{yr}$, and it is possible that the defect they demonstrated was secondary to age-related mucosal damage. De Rooij et al. (23) also drew similar conclusions from in vitro studies of ileal mucosal taurocholate uptake in two $\mathrm{CF}$ subjects, in whom bile acid uptake was low but not abnormal compared with controls. Balistreri et al. (24), on the other hand, have shown a blunted postprandial rise in serum glycocholate in $\mathrm{CF}$ which could be corrected by pancreatic enzyme replacement. They concluded from this indirect measure of ileal function that ileal active transport of bile acids was normal in CF. Further, Roller and Kern (25) made similar conclusions using a $\left[1-{ }^{14} \mathrm{C}\right]$ cholylglycine breath test in adolescent CF subjects, although subjects in this study had virtually normal fecal bile acid loss.

The concentrations of bile acids used in perfusates in the current study were more than their respective $\mathrm{K}_{\mathrm{m}}[0.6 \mathrm{mmol} /$ liter for taurocholate in man (12) and $0.18 \mathrm{mmol} /$ liter for glycocholate in the rat (26)]. These conditions would normally favor passive rather than active bile acid absorption. However, predominately passive absorption of glycocholate would be expected to result in a linear increase in uptake values with increasing intraluminal bile acid concentration. No such relationship was found herein. Ileal passive absorption of both glycocholate and taurocholate appears to be negligible (12); thus the relatively decreased uptake of taurocholate in $\mathrm{CF}$ and control subjects for perfusates of $C F \mathrm{G} / \mathrm{T}$ ratio most likely represents competetitive inhibition of taurocholate uptake by the higher glycocholate concentration rather than resulting from passive absorption. This conclusion is consistent with the similarity of uptake values for taurocholate (at normal G/T ratio) and for glycocholate; uptake values of both bile acids are similar in normal man (12). Thus the bile acid absorption demonstrated was almost certainly active for both taurocholate and glycocholate. Although active bile acid transport is absent in the newborn dog it develops rapidly in the neonatal period, reaching adult levels by 5 wk of age (22), and by 3 wk of age in the rat (19). The apparent predominance of active uptake in the human subjects studied is consistent with similarly rapid development of the transport system in man. The bile acid concentrations were similar to those used in vitro by Fondacaro et al. (9) $(0.1,1.0$, and $10.0 \mathrm{mmol} / \mathrm{liter})$ and to those of the ileostomy fluid of CF subjects in our study before perfusion. The concentrations used thus appear to have been appropriate for the pathophysiology of CF.

Taurocholate and glycocholate uptake during perfusion of a solution of physiologic $\mathrm{G} / \mathrm{T}$ ratio, $\mathrm{pH}$, and electrolyte composition was similar in both $\mathrm{CF}$ and control subjects (Table 2) but the values for taurocholate were lower than those reported by Krag and Phillips (12) in normal adults $(0.4 \mu \mathrm{mol} / \mathrm{min} / \mathrm{cm}$ ileum when corrected for perfusate bile acid concentration). Several factors may contribute to the difference. The infusion of both bile acids together will have resulted in competitive inhibition (12) and the ileal uptake mechanisms may not have been fully mature in subjects in the current study. Also, Krag and Phillips (12) used a perfusate infusion rate of $10 \mathrm{ml} / \mathrm{min}$ whereas that used herein $(1.5 \mathrm{ml} / \mathrm{min})$ is similar to the normal ileal flow rate of about $0.67 \mathrm{ml} / \mathrm{min}(15)$; infusion rates above $7 \mathrm{ml} / \mathrm{min}$ may cause unphysiologic changes in intraintestinal pressure and volume (27).

The cause of excessive fecal bile acid loss in CF remains unexplained. Absorption of bile acids other than cholic acid conjugates was not assessed herein. Cholic acid conjugates do, however, appear to be especially susceptible to malabsorption in $\mathrm{CF}$, both in relation to, and independent of, pancreatic insufficiency (28). The current study showed persistent excretion of bile acids in CF subjects compared with controls in the presence of similar bile acid uptake values, suggesting an increased bile acid load from the proximal ileum in the CF subjects. The study did not examine the effect on bile acid absorption of intraluminal factors such as unhydrolyzed triglycerides and unhydrolyzed phospholipids, precipitation of bile acids in the more acidic CF duodenum, and adsorption of bile acids to food residues. These factors remain possible explanations for excessive fecal bile acid loss in CF (2).

Acknowledgments. The authors thank Mr. K. Little, Director of Surgery, Adelaide Children's Hospital and the Royal Alexandra Hospital for Children, Camperdown, NSW, Australia, for providing access to patients, and Mr. T. A. Robb for his valuable comments.

\section{REFERENCES}

1. Weber AM, Roy CC, Morin CL, Lasalle R 1973 Malabsorption of bile acids in children with cystic fibrosis. N Engl J Med 289:1001-1005

2. Weber AM, Roy CC 1985 Bile acid metabolism in children with cystic fibrosis. Acta Paediatr Scand (Suppl) 317:9-15

3. Watkins JB, Tercyak AM, Szczepanik P, Klein PD 1977 Bile salt kinetics in cystic fibrosis: influence of pancreatic enzyme replacement. Gastroenterology 73:1023-1028

4. Tarver H 1963 Metabolism of amino acids and proteins. In: Roullier C (ed) The Liver. Academic Press, New York, pp 449-548

5. Robb TA, Davidson GP, Kirubakaran C 1985 Conjugated bile acids in serum and secretions in response to cholecystokinin/secretin stimulation in children with cystic fibrosis. Gut 26:1246-1256

6. Harries JT, Muller DPR, McCollum JPK, Lipson A, Roma E, Norman AP 1979 Intestinal bile salts in cystic fibrosis. Arch Dis Child 54:19-24

7. Roy CC, Weber AM, Morin CL, Combes JC, Nustle D, Megevand A, Lasalle R 1977 Abnormal biliary lipid composition in cystic fibrosis: effect of pancreatic enzymes. N Engl J Med 297:1301-1305

8. Darling PB, Lepage G, Leroy C, Masson P, Roy CC 1985 Effect of taurine supplements on fat absorption in cystic fibrosis. Pediatr Res 19:578-582

9. Fondacaro JD, Heubi JE, Kellogg FW 1982 Intestinal bile acid malabsorption in cystic fibrosis: a primary mucosal cell defect. Pediatr Res 16:494-498

10. Gibson LE, Cooke RE 1959 A test for concentration of electrolytes in sweat in cystic fibrosis of the pancreas utilizing pilocarpine by iontophoresis. Pediatrics 34:125-130

11. Torres-Pinedo R, Rivera CL, Fernandez S 1966 Studies on infant diarrhoea. II. Absorption of glucose and net fluxes of water and sodium chloride in a segment of the jejunum. J Clin Invest 45:1916-1922

12. Krag E, Phillips SF 1974 Active and passive bile acid absorption in man: perfusion studies of the ileum and jejunum. J Clin Invest 53:1686-1694 
13. Soergel KH 1968 Inert markers. Gastroenterology 54:449-452

14. Krejs GJ, Fordtran JS 1978 Physiology and pathophysiology of ion and water movement in the human intestine. In: Sleisenger MH, Fordtran JS (eds) Gastrointestinal Disease, 2nd ed. WB Saunders, Philadelphia, pp 297-310

15. Whalen GE, Harris JA, Geenen JE, Soergel KH 1966 Sodium and water absorption from the human small intestine: the accuracy of the perfusion method. Gastroenterology 51:975-984

16. Robb TA, Davidson GP 1984 Analysis of individual bile acids and their glycine/taurine conjugates by high-performance thin-layer chromatography and densitometry. Anal Clin Biochem 21:137-140

17. Oppe TE, Gibbs IE 1958 Sulphobromophthalein excretion in premature infants. Arch Dis Child 34:125-130

18. Fordtran JS, Rector FC, Ewton MF, Soter N, Kinney J 1965 Permeability characteristics of the human small intestine. J Clin Invest 44:1935-1944

19. Barnard JA, Ghishan FK, Wilson FA 1985 Ontogenesis of taurocholate transport by rat ileal brush border membrane vesicles. J Clin Invest 3:869-873

20. Swinscow TDV 1977 Statistics at Square One, 2nd ed. Mendip, Bath, pp 5861

21. Davidson GP, Cutz E, Hamilton JR, Gall DG 1978 Familial enteropathy: a syndrome of protracted diarrhoea from birth, failure to thrive and hypoplastic villus atrophy. Gastroenterology 75:783-790
22. Lester R, Smallwood RA, Little JM, Brown AS, Piasecki GJ, Jackson BT 1977 Fetal bile acid metabolism: the intestinal absorption of bile salt. J Clin Invest 59:1009-1016

23. De Rooij FWM, Van Den Berg JWO, Sinaasappel M, Bosman-Jacobs EP, Touw-Blommesteijn AC 1985 Bile acid malabsorption in cystic fibrosis: membrane vesicles, a tool for revealing the role of the ileal brush border membrane. Acta Paediatr Scand (Suppl) 317:28-30

24. Balistreri WF, Suchy FJ, Heubi JE 1980 Serum bile acid response to a test meal stimulus: a sensitive test of ileal function. Gastroenterology 96:582589

25. Roller RJ, Kern F 1977 Minimal bile acid malabsorption and normal bile acid breath tests in cystic fibrosis and acquired pancreatic insufficiency. Gastroenterology 72:661-665

26. Schiff ER, Small NC, Dietschy JM 1972 Characterisation of the kinetics of the passive and active transport mechanisms for bile acid absorption in the small intestine and colon of the rat. J Clin Invest 51:1351-1362

27. Fordtran JS 1966 Marker perfusion techniques for measuring intestinal absorption in man. Gastroenterology 51:1089-1093

28. Colombo C, Roda A, Roda E, Buscaglia M, dell'Agnola CA, Filippetti P Ronchi M, Sereni F 1984 Bile acid malabsorption in cystic fibrosis with and without pancreatic insufficiency. J Pediatr Gastroenterol Nutr 3:556-562 